\title{
Dual approach for Difficult Intracranial Lesions and their Outcome in BSMMU: Experience of Two Cases
}

\author{
Raut VK ${ }^{1}$, Arifin MS ${ }^{1}$, Rahman MN ${ }^{1}$, Obaida ASMA ${ }^{2}$, Rahman $A^{3}$, Khan AH $^{4}$
}

Conflict of interest: There is no conflict of interest relevant to this paper to disclose.

Funding Agency: was not funded by any institute or any group.

Contribution of Authors: Principal Investigator and Manuscript preparationData collection-

Scalp block with anaesthesia-

Editorial formatting-

Copyright: @2020bang.BJNS published by BSNS. This article is published under the creative commons CC-BY-NC license. This license permits use distribution (https://creativecommons. orgf/licences/by-nc/4-0/)reproduction in any medium, provided the original work is properly cited and is not used for commercial purposes.

Received: 22.08.19

Accepted: 13.11 .19

\begin{abstract}
:
Some lesions in the brain are difficult to approach through a single common route / trajectory. For those, dual approach combined together may ensure easier safe removal with better outcome as we had lesions like left petroclival meningioma \& large craniopharyngioma.

Methods Two patients, one left petroclival meningioma and one suprasellar craniopharyngioma with intraventricular extension underwent surgery with dual approach at the Neurosurgery department, BSMMU. After detailed clinical and radiological evaluation, the left petroclival meningioma patient was planned for a combined pre and post sigmoid petrosectomy and retromastoid retrosigmoid route. These were accomplished in two stages, three months apart. The craniopharyngioma patient with intraventricular extension underwent surgery through pterional transsylvian and frontal anterior trans-callosal approach in a single sitting.
\end{abstract}

Bang. J Neurosurgery 2020; 10(1): 111-118

\section{Case 01:}

Petroclival meningioma:a twenty two years old female presented with headache, partial ptosis and lateral rectus palsy on left side.

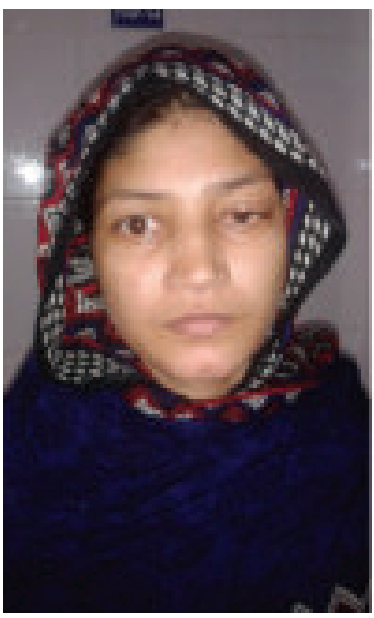

(a)

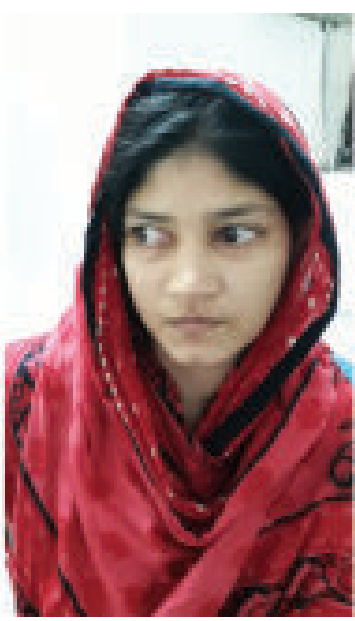

(b)



(c)

Fig.-1: $(a, b, c)$ shows the left sided partial ptosis \& left sided sixth cranial nerve palsy respectively.

1. Dr. Vijay Kumar Raut, Dr. Md. Samsul Arifin, Dr. Md. Nafaur Rahman, Resident, Dept. of Neurosurgery, Bangabandhu Sheikh Mujib Medical University, Dhaka, Bangladesh.

2. Dr. Abu Saleh Mohammad Abu Obaida, Medical Officer, Dept. of Neurosurgery, Bangabandhu Sheikh Mujib Medical University, Dhaka, Bangladesh.

3. Dr. Asifur Rahman, Associate Professor, Dept. of Neurosurgery, Bangabandhu Sheikh Mujib Medical University, Dhaka, Bangladesh.

4. Prof. Akhlaque Hossain Khan, Professor, Dept. of Neurosurgery, Bangabandhu Sheikh Mujib Medical University, Dhaka, Bangladesh. Address of Correspondence: Prof. Akhlaque Hossain Khan, Professor, Dept. of Neurosurgery, Bangabandhu Sheikh Mujib Medical University, Dhaka, Bangladesh. Mobile: 01711471153, E-mail: fahimshahriyer1@gmail.com 

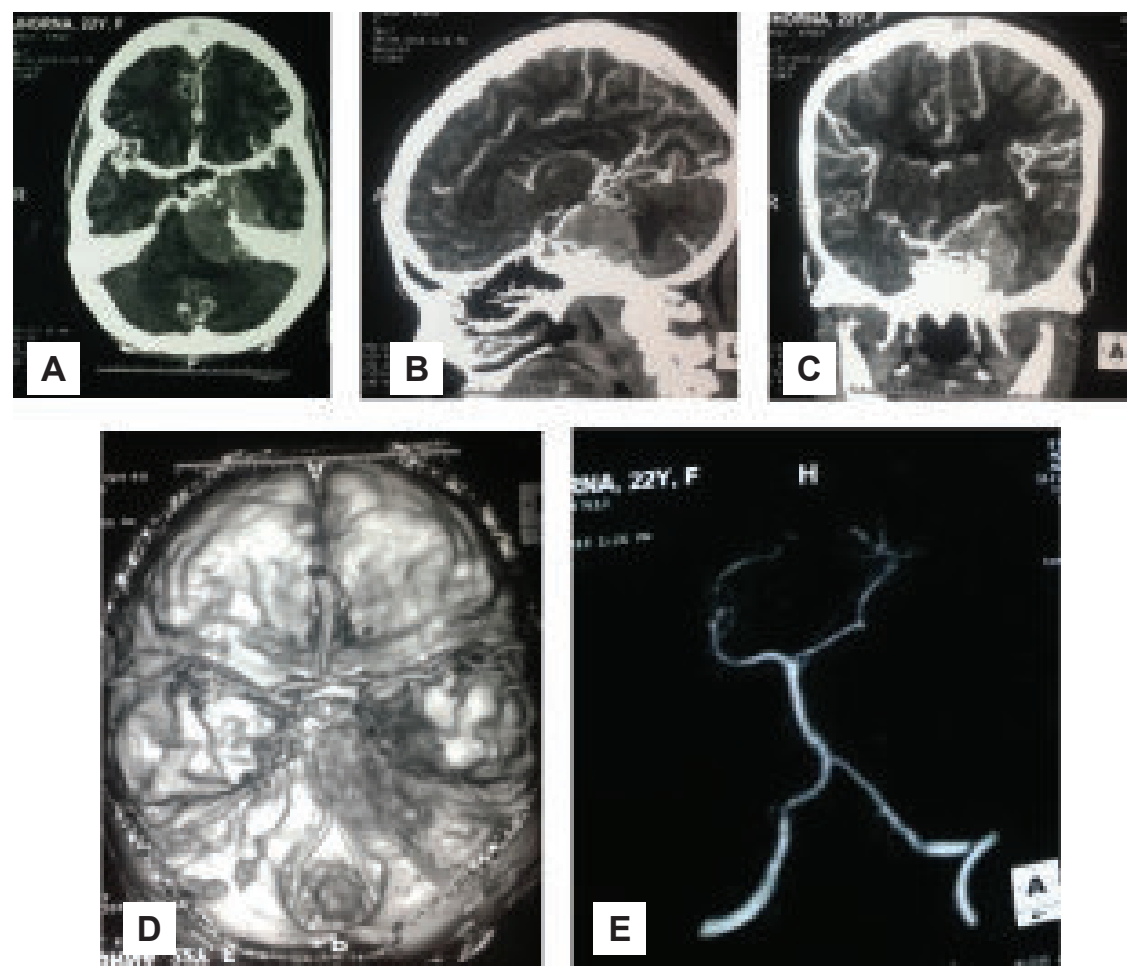

Fig.-2: (a) shows CECT axial, (b). sagittal, (c). coronal \& (d) \& $C$ CT angiogram of brain. Grade IV petroclival meningioma which pushes the vertebro-basilar complex on right side on angiogram


Fig.-3: shows MRI brain with contrast (a,b,c \&d) left sided grade IV petroclival meningioma

b.Surgical technique : combined petrosal craniotomy( middlle fossa \& presigmoid) followed by retrosigoid approach in two different settings. 

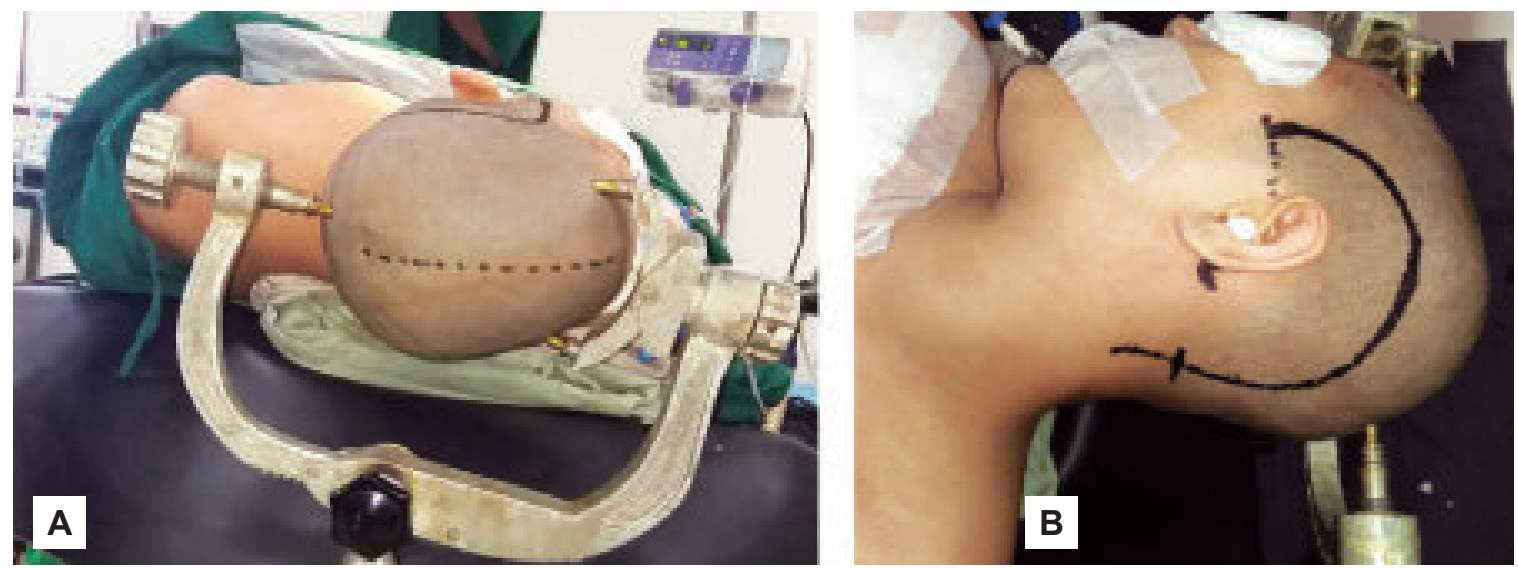

Fig.-4: (a \&b) shows the patient position and incision for combined petrosal craniotomy
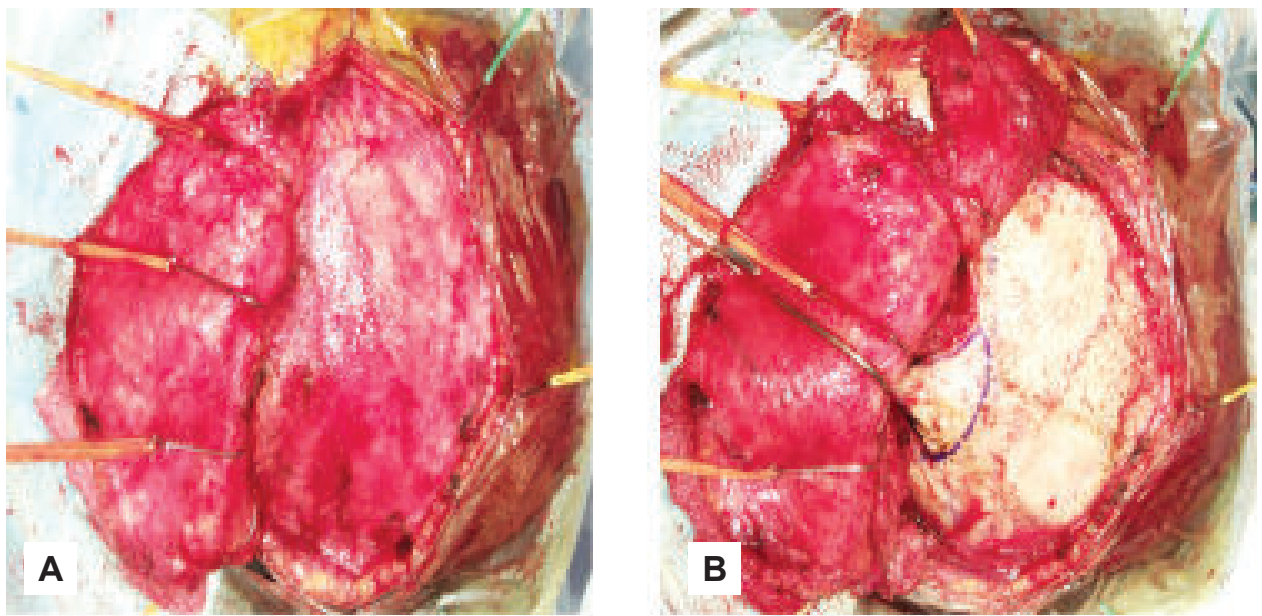

\section{B}
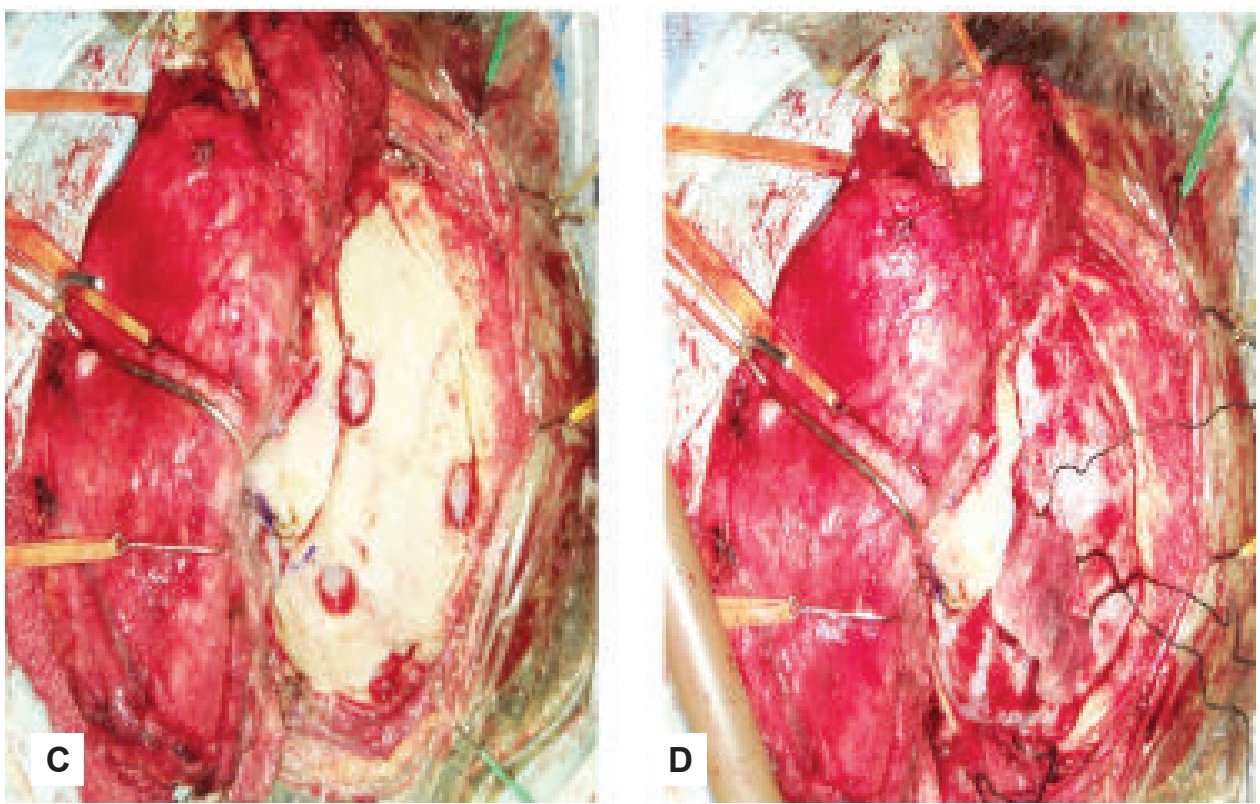

Fig.-5: ( $a, b, c \& d)$ shows the peroperative dissection of temporalis muscle, burrholes \& craniotomy for combined petrosal approach. 

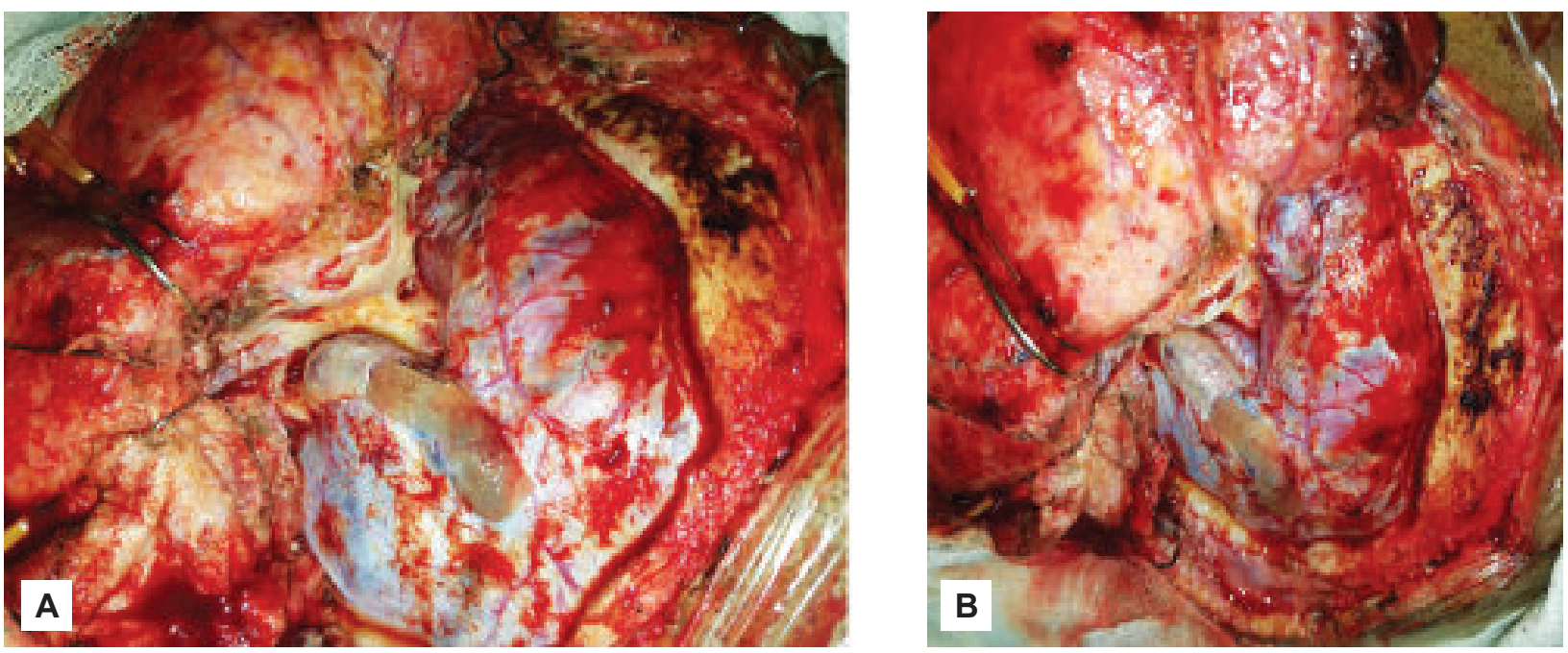

Fig.-6: $(a, b$,$) shows steps of mastoidectomy, skeletinisation of sigmoid sinus \& exposure of sino dural angle$ respectively.
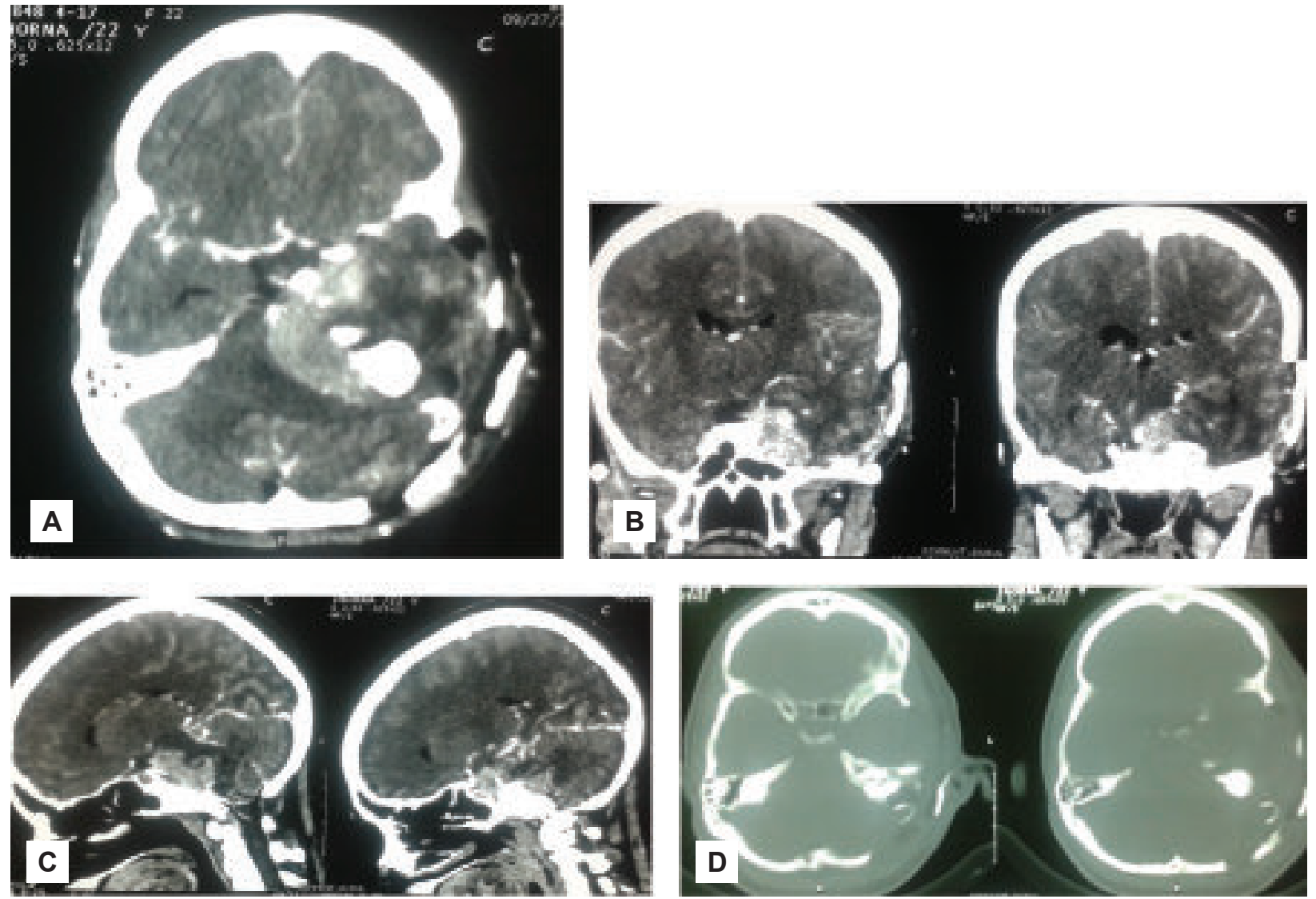

Fig.-7: (a,b,c \& d) shows post-operative CECT axial, coronal, sagittal \& bone window after combined petrosal craniotomy with subtotal removal respectively. (first stage surgery) 

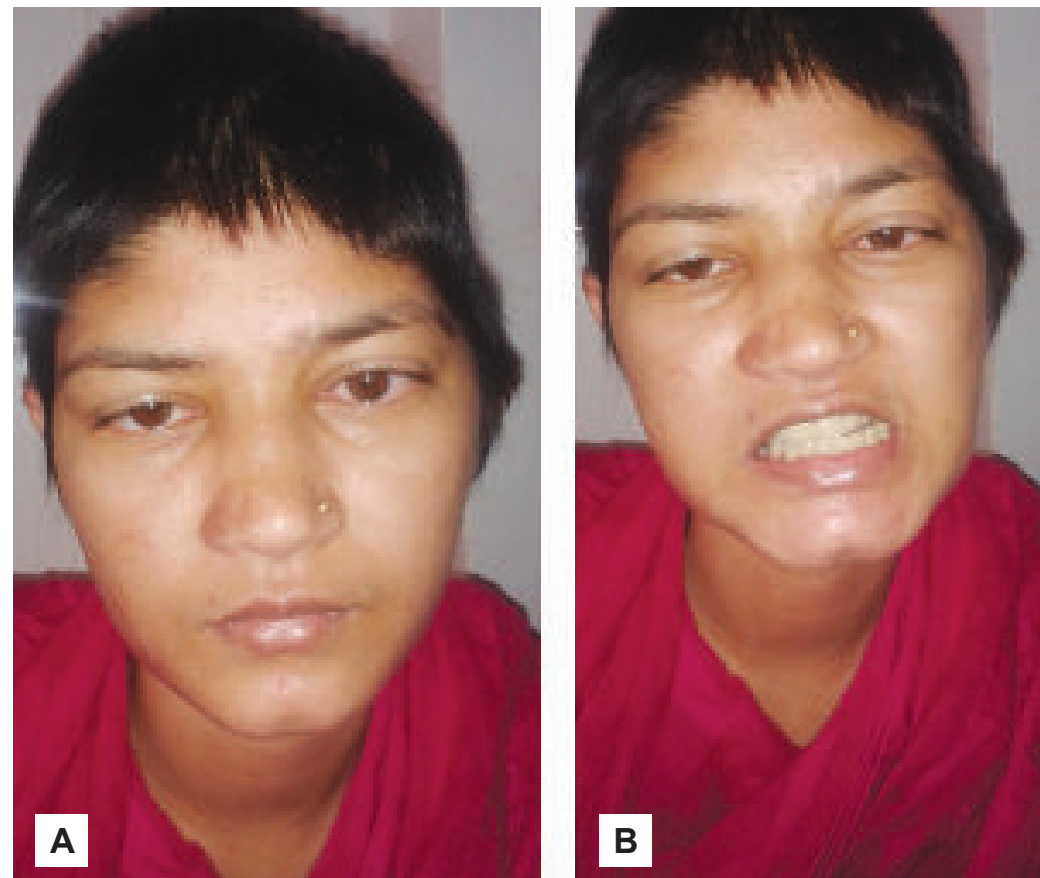

Fig.- 8 ( $a$ \& b) shows the post -op image of patient after combined petrosal craniotomy \& subtotal removal of tumor with improved partial ptosis \& grade II facial palsy respectively at three month of post op.
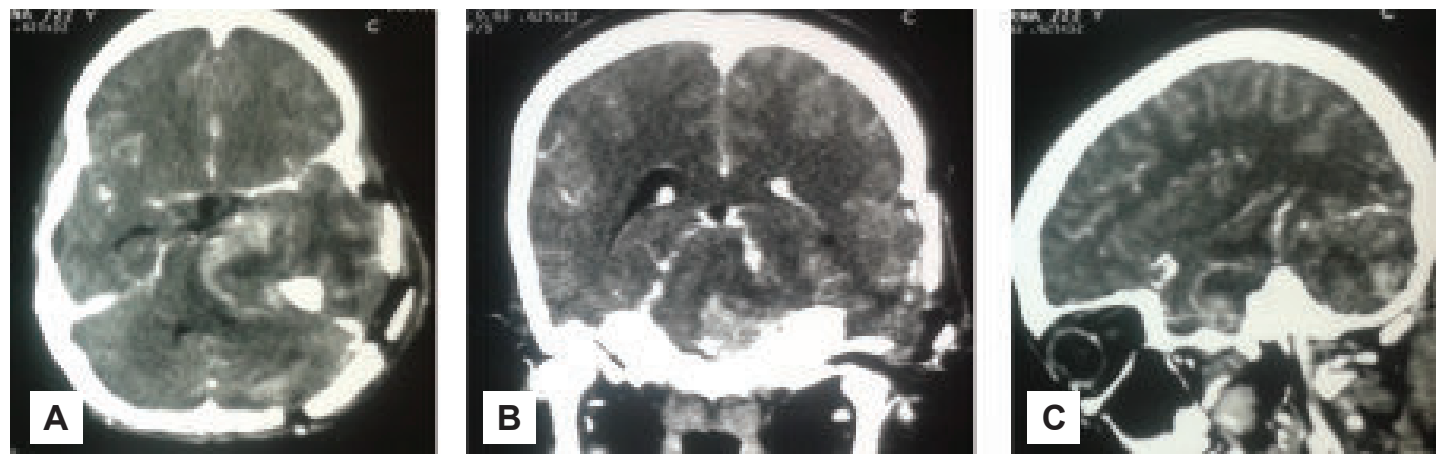

Fig.-9: ( $a, b$ \& $c$ ) shows CECT axial, coronal and saggital views after second stage of surgery, retrosigmoid approach respectively.
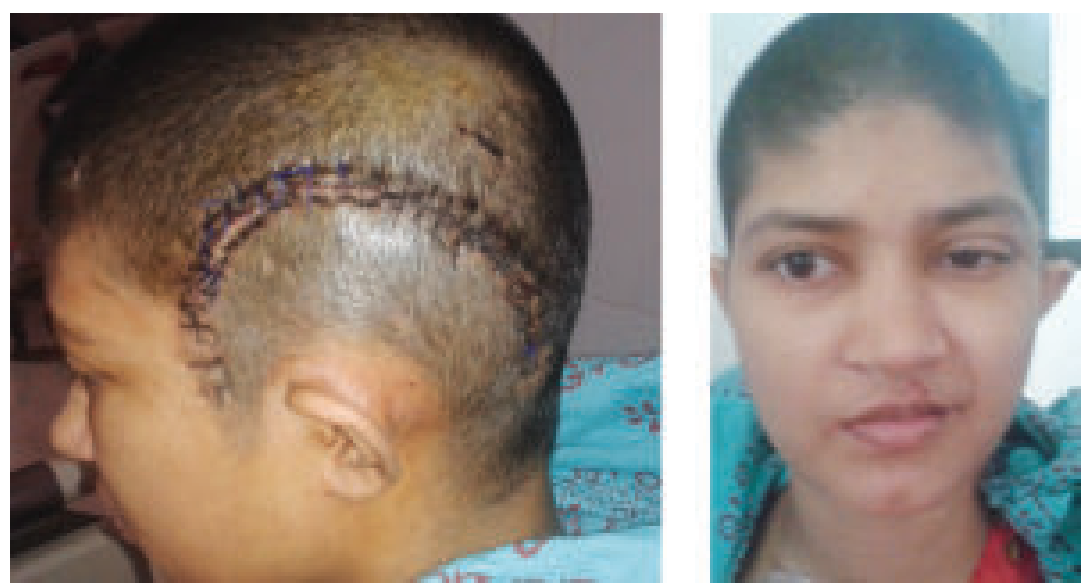

Fig.-10: (a \& b) shows post-op image of patient after second stage os surgery, retrosigmoid approach with healthy wound and grade III facial palsy respectively. at $7^{\text {th }}$ post-op day. 


\section{Case 02}

Craniopharyngioma: A nine years old female child presented with headache \& gradual loss of vision for one year. Leading her to blindness of right eye. Visual equity of right eye was limited to perception of light \& left eye was $6 / 18$. Hormonal profile was normal except serum cortisol which was subnormal.
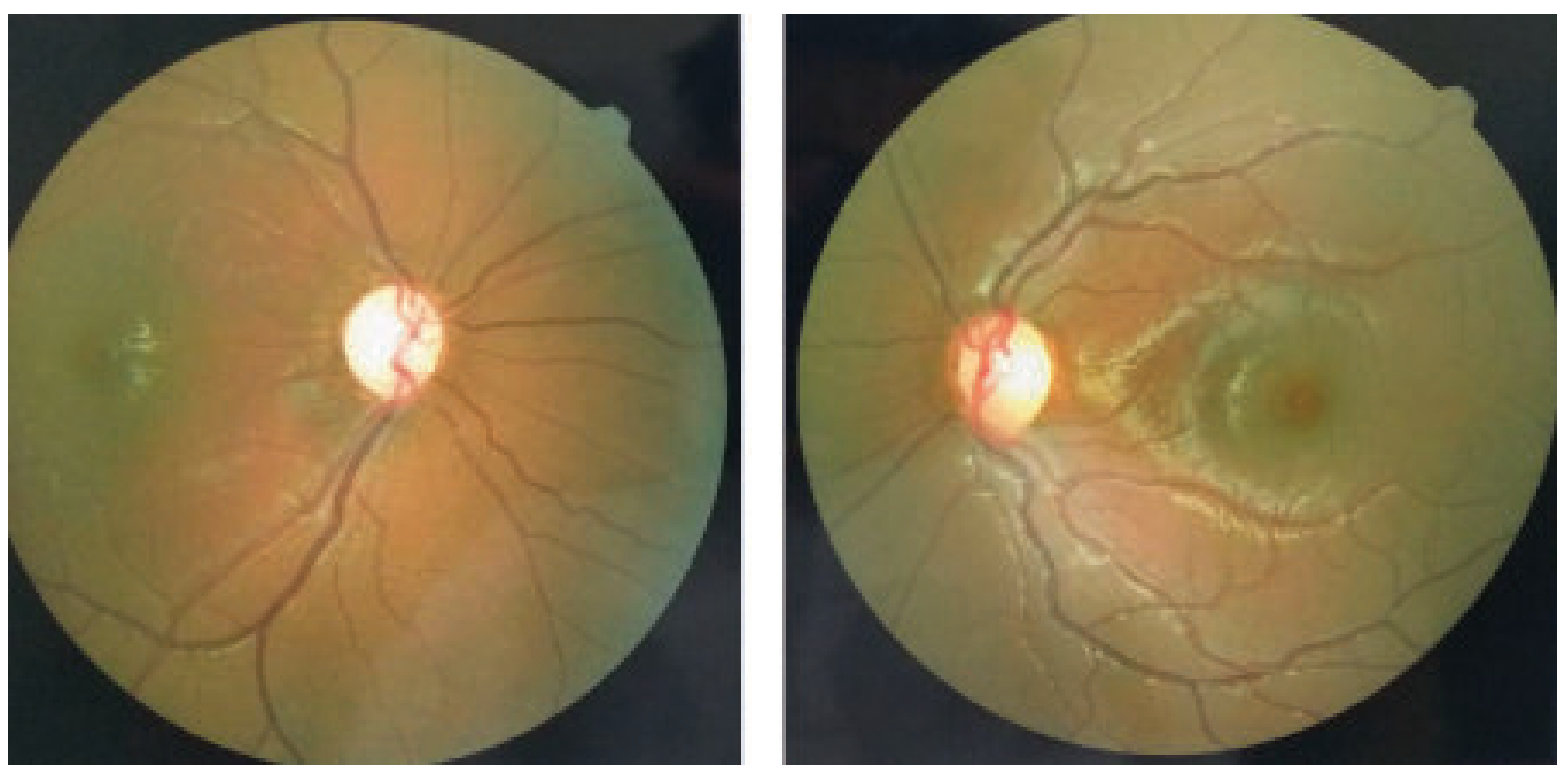

Fig.-1: shows fundus of patient with primary optic atrophy.
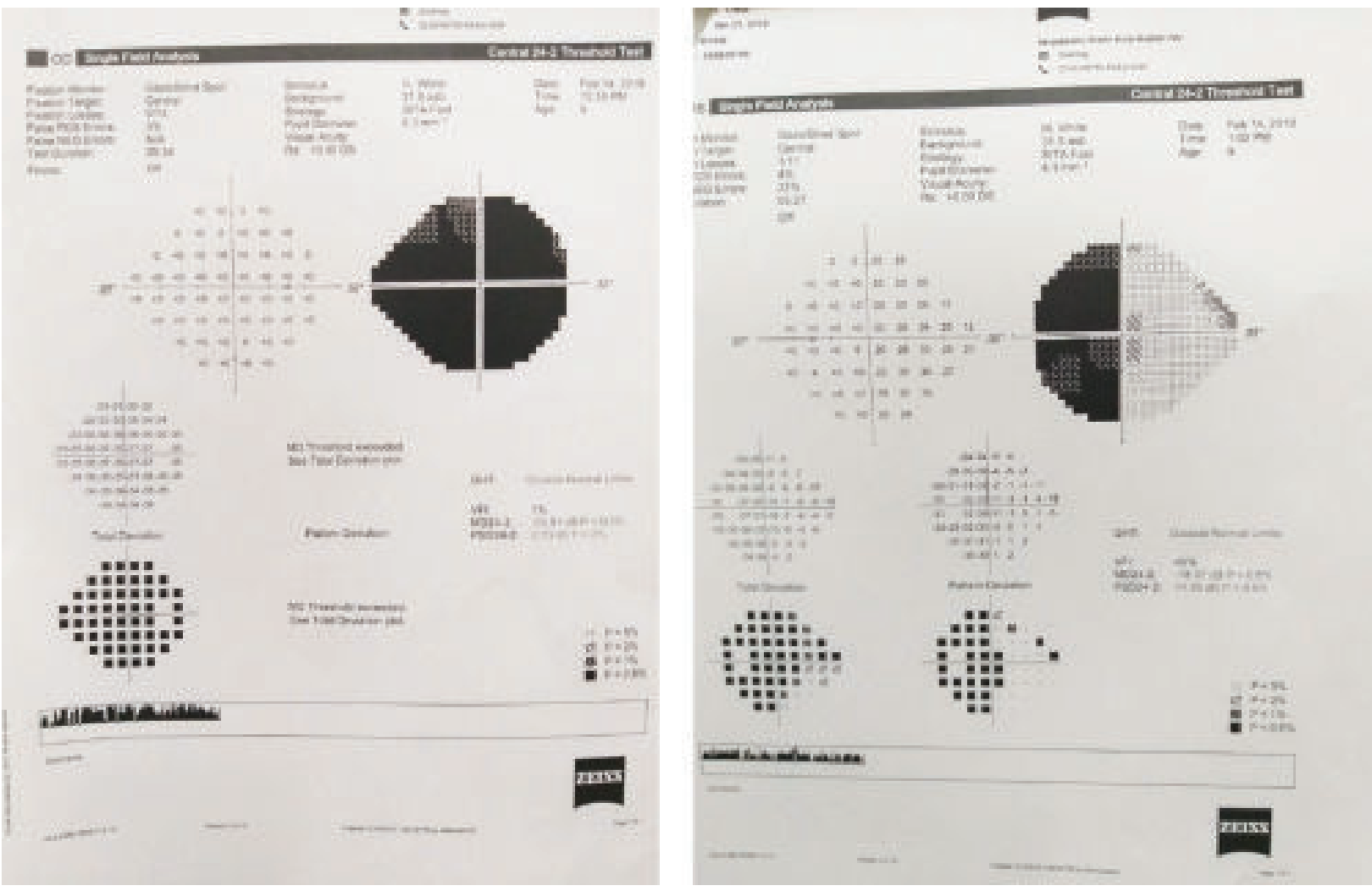

Fig.-2: shows humphrey visual field analysis of both eye of patient. Figure 02a shows involvement of all four quadrant where as figure $02 b$ shows bitemporal hemianopia. 



Fig.-3: (a,b,c \& d) shows $x$-ray skull with widened sella tursica and copper beaten appearance, MRI brain axial , saggital \& coronal views with large craniopharyngioma with suprasellar \& $3^{\text {rd }}$ ventricular extension. Respectively

Surgical approach:left sided pterional craniotomy \& near total removal of tumor by trans-sylvian \& interhespheric trans-callosal approach.


Fig.-4: (a ) shows the patient position, craniotomy site markings in relation with coronal suture and incision marking, ( 04 b ) shows dual approach craniotomy with durotomy (transylvian \& trans-callosal approach).


Fig.-5: (a, b \& c) shows post-op image of patient with healthy wound and with no focal deficits respectively. 

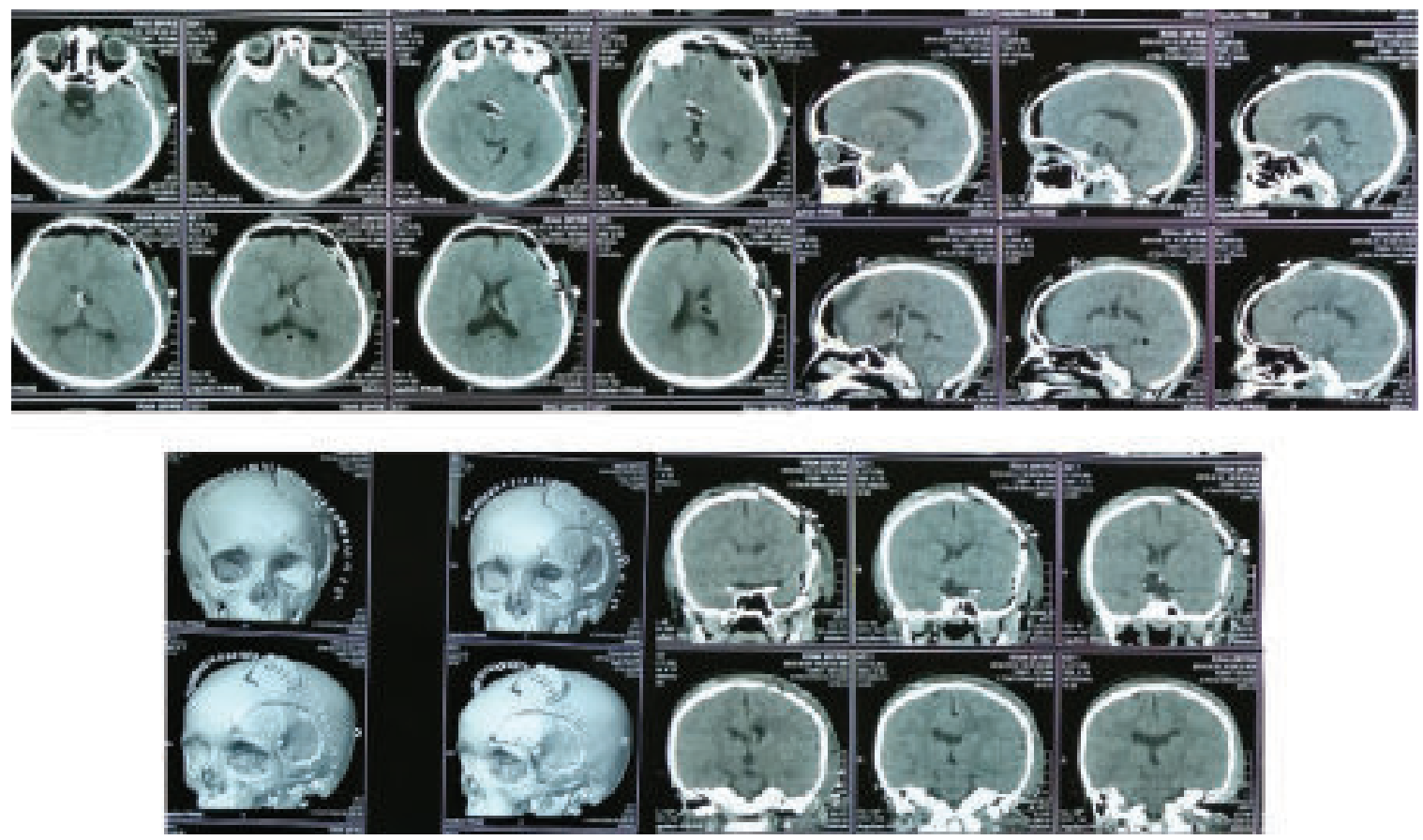

Fig.-6: (a,b,c \& d) shows post -op image, CT head axial, coronal , saggital with 3D reconstruction of bone respectively after dual approach with transylvian \& trancallosal approach with near total removal of tumor.

\section{Discussion:}

In case of left sided petroclival meningioma we performed combined petrosal craniotomy \& subtotal resection of middle fossa portion of tumor by subtemporal aproach. portion of tumor in posterior fossa was approached by pre-sigmoid aproach\& second stage of surgery in three months of interval by retromastoid aproach via previous incision. The sub total removal was done except tumor encasing the basilar artery \& infiltrating the brain stem.

For our second case of craniopharyngioma we choosed dual aproach as because lesion was huge. We performed neartotal removal via trans-sylvian \& trans-callosal approach.the capsule infiltrated to wall of third ventricle was left in situ

\section{Conclusion:}

Though dual approach is not performed very often in common neurosurgical practice. Dual approach can be beneficial for safe and satisfactory removal in cases of some extensive lesions like huge craniopharyngioma and formidable intracranial lesions like higher grade of petroclival meningioma.

\section{References:}

1. Lubuulwa J, Lei T. Pathological and topographical classification of craniopharyngiomas: a literature review. Journal of neurological surgery reports. 2016 Jul;77(03):e121-7.

2. Al-Mefty O, Fox Sr JL, Smith RR. Petrosal approach for petroclival meningiomas. Neurosurgery. 1988 Mar 1;22(3):510-7.

3. Cho CW, Al-Mefty O. Combined petrosal approach to petroclival meningiomas. Neurosurgery. 2002 Sep 1;51(3):708-18.

4. Ichimura S, Kawase T, Onozuka S, Yoshida K, Ohira T. Four subtypes of petroclival meningiomas: differences in symptoms and operative findings using the anterior transpetrosal approach. Acta neurochirurgica. $2008 \mathrm{Jul}$ 1;150(7):637-45.

5. Pascual JM, González-Llanos F, Barrios L, Roda JM. Intraventricular craniopharyngiomas: topographical classification and surgical approach selection based on an extensive overview. Acta neurochirurgica. $2004 \mathrm{Jul}$ 1;146(8):785-802.

6. Ya_argil MG, Curcic M, Kis M, Siegenthaler G, Teddy PJ, Roth P. Total removal of craniopharyngiomas: approaches and long-term results in 144 patients. Journal of neurosurgery. 1990 Jul 1;73(1):3-11. 